\title{
Conceptual Evolution of the Sequences and its Transition from High School to University in Morocco
}

\author{
Elarif Khaoula ${ }^{1}$, Hassouni Taoufik ${ }^{2} \&$ Bouazza El Wahbi ${ }^{1}$ \\ ${ }^{1}$ Laboratory of Analysis and Geometry of Application, Ibn Tofail University, Kenitra, Morocco \\ ${ }^{2}$ Regional Centre for Education and Training Trades, Meknes, Morocco \\ Correspondence: Khaoula.Elarif, Department of mathematics, University Ibn Tofail, Kenitra, Morocco.
}

Received: January 6, 2020

Accepted: August 17, 2020

Online Published: August 18, 2020

doi:10.5430/ijhe.v9n6p26

URL: https://doi.org/10.5430/ijhe.v9n6p26

\begin{abstract}
In this article, we present the question of our didactic research on the relative conceptual evolution and transition from high school to university in Morocco. We focused on the difficulties encountered by students in the first year of the Physics Sciences using a questionnaire which aims at evaluating the evolution of the concept of "Sequences" from high school to university, this one covers the basic concepts already taught during the last year of high school and second semester of university. The analysis of the student's productions revealed several didactic obstacles originating from previous misconceptions taught at high school. The study results show a broad gap between the knowledge to teach and the knowledge taught at university. As a result, considerable efforts must be devoted to minimize this gap and resolve the problems identified in our study.
\end{abstract}

Keywords: didactic transition; high school; conceptual evolution; university; the sequences

\section{Introduction}

While examining the literature, we have found an old application of the sequences through the "Babylonian algorithm," which allows approaching the number $(\sqrt{ } 2)$ by arbitrarily close fractions. In one of his texts "of the measurement of the circle," Archimedes used the sequences to have an approximation $\pi$. on the one hand, the notion of Sequence appeared from the beginning of mathematics, more or less explicitly. It was implicit in Euclid's methods (See the comparison of lengths by dichotomy), more explicit in Archimedes's work. On the other hand, the notion "limit of a Sequence" remained unclear until the 17 th century.

In Morocco, in the last year of high school, the pedagogical guidelines (2007) dealt with the generalities of the numerical Sequences. They elaborated a specific characteristic of Arithmetic and Geometric Sequences. They also involved students in solving a variety of problematic situations to improve the students' abilities to reason and argue the usefulness of this concept during the learning.

However, the final phase of the high school makes the objective of learning broader. The guidelines define the skills expected in relation to this concept including the ability to demonstrate this formula $\left(\mathbf{U}_{\mathbf{n}+1}=\mathbf{a} \mathbf{U}_{\mathbf{n}}+\mathbf{b}\right)$. The efforts will be instructed to the study of the behaviour of a numerical sequence. They also offer the calculation techniques and problem solving tools.

The chapter of the Sequences is not restricted to a single unit; it's presenting the concept "sequence" through several demonstrations and applications. The unit includes real numbers and Algebraic argumentation formulas. The transition of the concept "Sequence" varies according to the relation student-teacher from high school to university. The high school learning must be acquired and assimilated to deal with the usual concept that is presented in a different way. This approach will either lead to the conceptual enrichment of the student's mental model or to a conceptual obstacle along his new learning process.

At Ibn Tofail University, the teachers start the chapter of sequences by presenting a direct definition. The higher education teacher explains the notion according to the chosen registers (arithmetic; algebraic; semiotic).He makes a concept transition from a simple arithmetic expression to a new numeric presentation. The level and the process of learning become advanced from (U: IN---IR) to a general term (n----U (n)). The higher education is a major challenge for the teachers. A higher education teacher faces three major challenges: the multiplication of knowledge, the needs of the world of work and the students (Maroy, 2006). 
The knowledge is growing at an exponential rate. This availability leads the university to teach differently. The teacher is confronted with a large audience of students. They are various and heterogeneous. They have a different socio-cultural background, needs, interests and learning profiles (Maroy, 2006).

The work market requires from universities to develop high-level cross-curricular skills. They are defined as the ability to solve problems, work under pressure without caring about space and time, take the responsibility and the initiative, organize resources and manage time" (Poteaux, 2013, p. 3). The student adapts himself to change and the communication (Demougeot-Lebel et al., 2012). All these challenges have led to the intensification, diversification and complexity of the teacher's tasks (Maroy, 2006).The work market has "considerably transformed the conditions of the teaching practice at university» (Demougeot-Lebel et al., 2012, p. 116).

\section{Previous Studies}

Robert (1982) and Boschet (1983) pointed out that the student faced didactic obstacles in order to master the concept of "sequence". The learning obstacles are caused by the breakdown of the didactic contract between student-teacher relations during the learning process. The divergence of the didactic transition leads to a broad gap between learned knowledge and the knowledge to be taught.

Brousseau (1983) found that the error in the learning and construction of knowledge is not strictly due to ignorance or chance. The impact of an earlier knowledge that has been introduced has proved to be wrong or inappropriate in didactic situations. This conception will contribute to conceptual obstacles that will be difficult to eliminate or modify.

The studies carried out in 2015 by (Bouchra LITIM; Moncef ZAKI; Amina BENBACHIR), highlighted the concept of numerical sequence. They wanted to study the learning difficulties. That work targeted the first-year university students. We distributed a MCQ test for the Mathematics and Physics Sciences option. We analysed the students' productions at the end of the semester. That research revealed several problems in terms of

pre required knowledge. The Didactic Transition influenced the didactic contract between student-teacher. That issue proved that traditional higher education learning was poorly adapted to the teaching of the numerical "Sequence".

\section{Definitions}

\subsection{What is a Sequence?}

A sequence is a list of numbers. Any time you write numbers in a list format, we are creating a sequence. We usually identify it as a sequence with the notation

$\mathrm{U}_{\mathrm{n}}=1,2,3,4,5,6 \ldots$

There is some type of pattern to a sequence. In the sequence above, we add one to each term to get the next term. A term of a sequence is just a number that is in the sequence. Terms can be identified by their location. We note the 1 st term in a sequence as $\mathrm{U}_{1}$ and we call the 5 th term in the sequence $\mathrm{U}_{5}$.We describe the pattern in the sequence as adding one to each term to get the next term. We can express this as a recursive formula by writing

$\mathbf{U}_{\mathbf{n}}=\mathbf{U}_{\mathrm{n}-1}+\mathbf{1}$

\subsection{Arithmetic Sequence}

In an Arithmetic Sequence the difference between one term and the next is a constant. In other words, we just add the same value each time. The sequence $U_{n}$ is Arithmetic if: $r \in R$ and for $n \geq n_{0}$.

$\mathbf{U}_{\mathbf{n}+1}=\mathbf{u}_{\mathbf{n}}+\mathbf{r}$.

The real number " $r$ " is defined as the reason of the Arithmetic Sequence $U_{n}$. " $r$ " is called the "common difference" between terms.

\subsection{Geometric Sequences}

In a Geometric Sequence, each term is found by multiplying the previous term by a constant.

In general we write a geometric sequence

$\mathbf{U}_{\mathbf{n}+1}=\mathbf{U}_{\mathbf{n}} \times \mathbf{q}$.

Where: $\mathbf{U}_{\mathbf{n}}$ is the first term, and $\mathbf{q}$ is the factor between the terms (called "common ratio"

\section{Summing an Arithmetic Series}

$$
\sum_{k=p}^{n} u_{k}=u_{p}+u_{p+1}+\ldots+u_{n}=(n-p+1) \times \frac{u_{p}+u_{n}}{2}
$$




\section{Summing a Geometric sequence:}

$$
\sum_{k=p}^{n} u_{k}=u_{p}+u_{p+1}+\ldots+u_{n}=u_{p} \times \frac{1-q^{n-p+1}}{1-q}
$$

\subsection{Problematic}

The present work defines the context of our didactic research. Our problematic discusses the conceptual evolution of a "Sequence". We seek to define/characterize the conceptual evolution of the numerical sequence and its transition from high school to university.

The research will highlight the teaching methods of this concept at high school. High school students have many difficulties in their studies of Sequences. We take into consideration the importance of the students' mental models during the learning process and the assimilation of knowledge in higher education period. The outline of our study is determined by considering the limitations of this conceptual evolution. The answers inform us about the teaching methods in both cycles. We present the following two research questions:

RQ1: Can we measure the level of the conceptual evolution of the sequence from high school to university?

RQ2: How can the students solve the problems related to the concept "sequence" after high school learning?

We hypothesize that several complex teaching problems prevent the evolution of our concept. This didactic obstacle reflects a detour during the learning process. The students are forced to adapt themselves to an intellectual change at university. Various hypotheses explain our problematic.

First, (Latifa Ouertatani \& Alain Dumon, 2011) reveal in their contribution that the general methodology of the calculation of $\mathrm{pH}$ did not seem to encourage the enriching of conceptual knowledge. They recommended interactions between the empirical and theoretical registers. That followed each other without links in Tunisian education. For the students, the difficulties encountered in their attempts to remember and use the "formulas" were notified.

Second, for the first year university students. According to (Claudia Corriveau EMF 2015), the higher education teachers should concentrate on the transitions of the concepts. They need to examine their ways of organising the knowledge and the objectives of the teaching process.

\section{Method}

The reference frameworks in Morocco (2007), specific to mathematics teaching in high school, drew some lines to be respected during the teaching practice. Starting from the concept of «the sequences» that we had privileged in terms of $\%$ importance, we mention the analytical aspect that requires the use of the geometric and arithmetic sequence in the study of sequence and the function: $\mathrm{U}_{\mathrm{n}+1}=\mathrm{f}\left(\mathrm{U}_{\mathrm{n}}\right)$.

At Ibn Tofail University in Kenitra (2019), our research site and sample source (140 students) was made on the first year students. The choice was at random at the speciality level (physics sciences) and also by gender (Male / Female). We studied the mathematics textbooks for the baccalaureate level and we used the hand-out written by the teacher. We deduced a list of didactic variables.

According to BROUSSEAU G. (1986) "A didactic variable of a situation is a variable that can be modified by the teacher, those modifications [the slightest] can significantly influence the student's behaviour and cause different procedures or types of responses". Six homogeneous and compatible didactic variables are defined to measure the conceptual evolution during the learning process and after teaching the concept [Table 1].

Table 1. Didactic Variables

\begin{tabular}{ll}
\hline VD 1 & Level of Formulation \\
\hline VD 2 & Level of Reasoning \\
VD 3 & Level of generalization "deduction" (high/low) \\
VD 4 & Number of new notions \\
VD 5 & Choice of Resolution Techniques \\
VD 6 & Status of tasks (Direct application/Demonstration) \\
\hline
\end{tabular}

Our study was based on a pre-test to validate the sample data. This leads to calculate the rationing accuracy of the test thanks to Cronbach who developed Cronbach's Alpha formula. Our test indicates the value of $\alpha=0.75$, According to Nunnaly (1967), for Alpha to be significant it must be $0.7<\alpha<1$. 
In our city, where access to university is not open, especially in the period of the exams, the study process seems to play a key role in achievement. In such a context, this process is often initiated much later than in more restrictive systems. It is therefore essential to analyse the successful impact of the study process among first-year students.

First, the study sample consisted of the physics sciences students. We noted that the sample size was not large enough to be analysed. As a result, we added mathematics sciences students to the first sample. The questionnaire was distributed in two different ways including direct contact with the students and Online (Google drive). The challenge was hard because we needed the answers in their final exams of the second semester(after teaching the concept chosen). We have collected 140 answers.

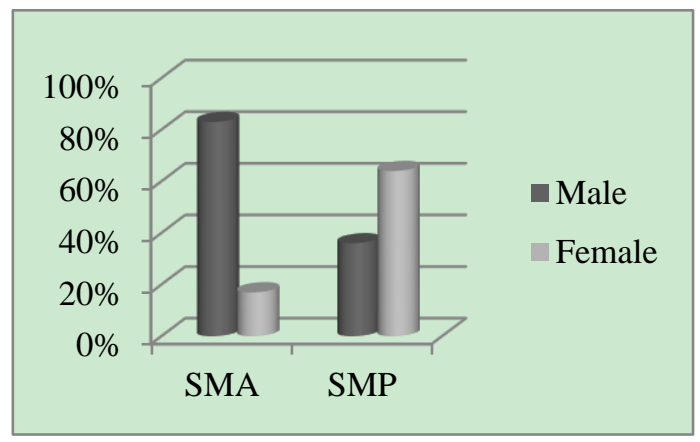

Figure 1. Distribution of students

\section{Results}

In this section, in order to focus on the learning evolution of the concept Sequence. We study the number of false and inadequate responses to our rating scale.

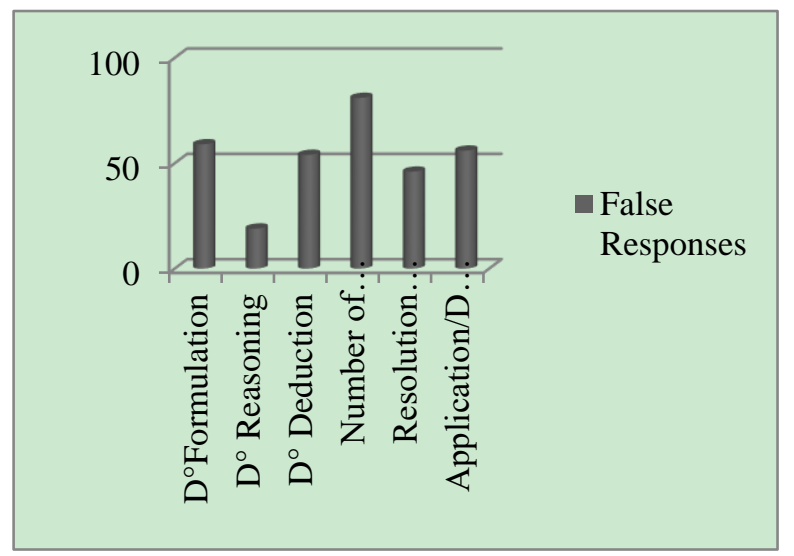

Figure 2. Distribution of incorrect answers /Didactic variable

From one hundred and forty students (both sections). 30 correct answers were just the half of the students who succeeded in the first level of the questionnaire; $\mathbf{3 7}$ students had the ability of reasoning and analysing their choices in the MCQ. It can clearly be seen that most of the students had difficulty applying and demonstrating new concepts (Sequence and a Function) such as the limit of the Function $\mathrm{f}\left(\mathrm{U}_{\mathrm{n}}\right)$. The 62\% inadequate responses explained the problems in the learning process and prerequisites already taught for that level. That result proved the gap in the didactic transition.

The student practiced some types of application and demonstration in the problems $(\mathbf{4 2 \%}$ of the sample wrote insignificant answers). In our analysis, we selected a question to each didactic variable showing the core concept of numeric Sequence. The errors reported in our survey were written as they were written in the students' productions.

\subsection{Impact of Gender on Mathematical Thinking}

Our study was randomized, with no gender bias in the sample selection. But at the end of the data collection, we found that the dominant with $70 \%$ of participants were Males.

(Zhu, Zheng 2007) reported that there were gender differences in mathematics problems solving; males performed better. That was related to cognitive abilities, together with psychological characteristics by experience and education. Male students were more likely to solve the problems successfully. 


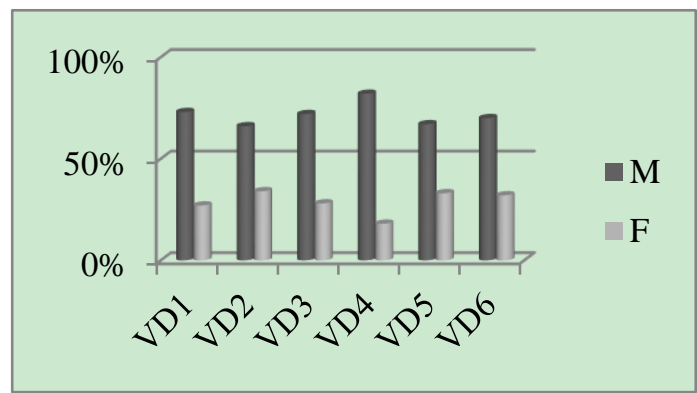

Figure 3.Distribution of correct answers/Gender

The choice of the speciality or the way to solve a mathematical problem may be the reason to find the $\mathbf{4 6 \%}$ difference between male and female. Most of the students replied without giving any importance to the justifications requested. In order to answer the questions asked, the students should have the ability to reason, but only $\mathbf{3 0 \%}$ of the girls were able to answer easily compared to $\mathbf{7 0 \%}$ of the boys. For a mathematician, finding a correct reply, with inconsistent justification, reflected a rupture in the acquirement of the knowledge.

\section{1) Degree of formulation}

Question $4: \mathrm{U}_{\mathbf{n}}$ defined by $\mathrm{U}_{\mathbf{n}+1}=3 \mathrm{U}_{\mathbf{n}}$ for everything $\mathbf{n} \geq \mathbf{0}$.
$\square \quad \mathrm{U}_{\mathbf{n}}$ is anthmetic
$\square \quad U_{n}$ is geometric
$\square \quad$ We can't conclude

On all copies 53\% of the incorrect answers, $40 \%$ of them were unjustified. The rest were able to write a justification. For example:

\section{A1 $U_{n}$ is positive so $U_{n}$ is geometric.}

A2 $U_{n+1}=3 U_{n}$, the function is increasing so it's geometric.

Those inconsistent responses revealed disruptions in high school achievement; the definition of a geometric and an arithmetical Sequence was not well assimilated by those students. The lesson of the sequences was presented in high school, that's why the evolution of the concept of "Sequence" has shown a breakthrough in terms of knowledge.

\section{2) Degree of reasoning}

$$
\begin{aligned}
& \text { Question 5: If }\left\{\begin{array}{c}
\mathrm{U}_{0}=-1 \\
\mathrm{U}_{\mathrm{n}+1}=2 \mathrm{U}_{\mathrm{n}}+3
\end{array}\right. \\
& \text { ․ } U_{n}=3^{n+1}-2 \\
& \text { ․ } U_{n}=2^{n+1} \\
& \text { 口 } U_{n}=2^{n+1}-3 \\
& \text { (]) } U_{n}=2^{n+1}-2
\end{aligned}
$$

Most of the students did not justify this question; More than $20 \%$ had wrong answers, here is one type of illogical reasoning:

\section{A1 $U_{n+1}=2 U_{n}+3$ Then $U_{n}=\left(U_{n+1}-3\right) / 2$}

During the teaching of this lesson, the teacher has detailed the calculation of $U_{n}$ from $U_{n+1}$. As it is an arithmetical sequence, the student must think about another way of reasoning (using the definition, demonstration).

\section{3) Degree of deduction}

Question 10: Is there a geometric and arithmetic sequence?

No, there is no numerical sequence

- Yes, if any geometric sequence of reason $\mathrm{q}=0$

$\square$ Yes, if any arithmetic sequence of $r=0$ 
We found $\mathbf{6 5 \%}$ of incorrect and unjustified responses. For this type of question, it's clear that the students did not use the definition adapted in high school and even during the teaching of this chapter at university (first year; second semester). This tells us that most students answered direct questions that were not implicit. Moreover, just $\mathbf{3 5 \%}$ of the students succeeded and applied their knowledge correctly.

\section{4) Number of new notions}

Question 11: In the sum of $\frac{\sin 2}{\mathrm{n}^{2}}+\cdots \cdots \cdots+\frac{\sin n}{\mathrm{n}^{2}}$ there are:
$\square \mathrm{n}$ terms
$\square \quad(\mathrm{n}+1)$ terms
$\square \quad(n-I)$ terms

In this question, we introduced the notion of "the Summing a sequence" and the (Sinus). More than 72.7\% of the students failed and were hindered by the appearance of the instruction. Knowing that the rule of calculation of the Summing did not change either at high school or university. On the other hand, students at university began to analyse the calculation process. Out of $\mathbf{1 4 0}$ students, only $\mathbf{4 2}$ justified their choices. Here are some of their answers:

\section{A1 n terms}

\section{A2 There is $\sin \mathbf{n}-\sin 2$ terms}

\section{A3 There are (n-2) terms}

The teacher gave a brief example of how to calculate the sum for this type of sequence. However, this question was chosen because it revealed the gap between what was explained by the teacher and what the student understood.

\section{5) Resolution technique}

$$
\begin{aligned}
& \text { Question 18: Either the sequence } \left.\quad \mathrm{U}_{\mathrm{n}}\right)_{\mathrm{az} 0} \text { arithmetic defined by : } \mathrm{U}_{\mathrm{n}}=\left\{\begin{array}{c}
\mathrm{U}_{0}=2048 \\
\mathrm{r}=-\frac{1}{2}
\end{array}\right. \text {, } \\
& \lim _{\mathrm{n} \rightarrow \infty} \mathrm{U}_{\mathrm{n}}=\text { ? } \\
& \text { a }+\infty \\
& \text { व }-\infty \\
& \square 0 \\
& \text { 1 Pas de limite }
\end{aligned}
$$

The failure rate of all the questions was particularly high, but surprisingly, $\mathbf{6 5 \%}$ of the students gave the right answers. Intuitively, they tried to reason using the information above. We noticed after reading their justifications; that majority did not know why they chose that answer. There were just $\mathbf{1 5}$ incorrect answers. The most common errors are:

\section{A1 $\operatorname{Lim} \mathrm{U}_{\mathrm{n}}=\operatorname{Lim} \mathrm{U}_{0}$; then $\operatorname{Lim} \mathrm{U}_{\mathrm{n}}=+\infty$ \\ A2 $r=-1 / 2 ; r$ negative so $\operatorname{Lim} U_{n}=-\infty$}

The sample had been able to determine the correct method of resolution for this operation "limit". There was difficulty in manipulating the definition of the Arithmetical sequence that went back to high school. There was also a lack of details, even for correct answers. Moreover, the professor's note "badly justified" appeared in all copies.

\section{6) Direct application/demonstration}

Question 16 : Let $\mathrm{U}_{\mathrm{n}}$ a geometric sequence defined by : $\left\{\mathrm{U}_{0}=1, \mathrm{q}=2, \mathrm{~S}_{\mathrm{n}}=15\right\}$

Determine for which integer $n$ we have a $S_{n}=15$ ?

$$
\begin{array}{ll}
\square & \mathrm{n}=3 \\
\square & \mathrm{n}=0 \\
\square & \mathrm{n}=-3
\end{array}
$$


We need to remind, that question evaluated the student's ability to analyse and follow the demonstration steps. The question would motivate the student to use all the knowledge in order to find the right choice. Almost half of the sample missed the correct answer, and $\mathbf{4 7 . 7 3} \%$ of the students used the clear solution to demonstrate their options. The success rate difference gave us $\mathbf{3 8 \%}$ Males.

There were only $\mathbf{2 0}$ correct answers. Frequent false answers are:

A1 $n=3, \quad S_{n}=U_{0}+q$;

A2 Knowing that the geometric sequence is written as follows: $U_{n+1}=q U_{n}$ then $n=\left(S_{n} / q+1\right)=3$;

A3 $\mathbf{S}_{\mathbf{n}}=\mathbf{U}_{\mathbf{n}+1}-\mathbf{U}_{0}=\mathbf{0}$.

The students justified their choices in a literary way and did not rely on mathematical taught arguments. The definition of $S_{n}$ was not used. This can be explained by the method the teacher used to solve that type of problem. Thus the fact of the didactic contract will appear after.

\section{Discussion}

Our goal in this study was focused on tracing the conceptual evolution of the Sequences from high school to university. The impact of the didactic transition changed the major elements of knowledge among the students.

The most students' errors reveal remarkable disruptions in the level of:

- The logical understanding of definitions;

- The analytical method of response that differs between direct resolution and lesson application;

- Reasoning correctly.

(Brousseau 2010.Hal) claimed that the source of the student's error came from:

- Identification of the concepts;

- The didactic treatment of educational obstacles

We can even mention some problems that have disrupted the performance of our evaluation:

- The motivation and time chosen for the requested evaluation;

- The stress the lessons;

- The random choice of answers and the speed.

\section{Conclusion}

The results of this experiment reveal that there is a gap between the knowledge to be taught and the real knowledge taught. Indeed, the analysis of the errors and difficulties found in students' productions allow us to put forward the strong hypothesis; the scientific debate permit the student to become involved in the construction of his knowledge. This encourages the emergence of cognitive conflicts necessary to understand. The conceptual evolution of the concept "Sequence" that was measured among university students. We conclude that the didactic transition and teaching practice influence the performance of the knowledge taught.

\section{References}

Artigue, M. (2009). L'enseignement des fonctions à la transition lycée-université. In Actes du XV e Colloque CORFEM, 2008, (25-44).

Biehler, R., Scholz, R. W., Strässer, R., \&Winkelmann, B. (Eds.). (2006). Didactics of mathematics as a scientific discipline, 13. Springer Science \& Business Media.

Bloch, I., \& Ghedamsi, I. (2005). Comment le cursus secondaire prépare-t-il les élèves aux études universitaires. Petit $x, 69,7-30$.

Briz-Ponce, L., Pereira, A., Carvalho, L., Juanes-Méndez, J. A., \& García-Peñalvo, F. J. (2017). Learning with mobile technologies-Students' behavior. Computers in Human Behavior, 72, 612-620. https://doi.org/10.1016/j.chb.2016.05.027

Brousseau, G. (1976). Epistemological Barriers and Problems in Mathematics.

Ghedamsi, I., \& Tanazefti, R. (2015). Difficulties in learning complex numbers at the end of High School. Petit $x, 98,29-52$. 
Litim, B., Benbachir, A., \& Zaki, M. (2014). Impact of previous conceptions in secondaryuniversity transition: the case of conversion of numerical sequences. International Journal of Research in EducationMethodology, 6(3), 896-903. https://doi.org/10.24297/ijrem.v6i3.3863

Litim, B., Zaki, M., \&Benbachir, A. Actes du Colloque EMF 2015. Conceptual difficulties of first-year university students with the notion of convergence of numeric sequences, 677-686.

OUERTATANI, L., \& DUMON, A. The high school-university transition and the conceptual evolution relating to $\mathrm{pH}$ calculations in Tunisia.

Zhu, Z. (2007). Gender differences in mathematical problem solving patterns: A review of literature. International Education Journal, 8(2), 187-203.

\section{Copyrights}

Copyright for this article is retained by the author(s), with first publication rights granted to the journal.

This is an open-access article distributed under the terms and conditions of the Creative Commons Attribution license (http://creativecommons.org/licenses/by/4.0/). 